\title{
Organização do trabalho hospitalar e os impactos na subjetividade do trabalhador de enfermagem
}

\author{
Hospital work organization and its impacts at nursing worker's subjectivity \\ Organización del tranajo hospitalário e impactos em la subjetividade del trabajador de enfermeira
}

Recebido: 07/02/2021 | Revisado: 16/02/2021 | Aceito: 18/02/2021 | Publicado: 27/02/2021

\author{
Silvio Arcanjo Matos Filho \\ ORCID: https://orcid.org/0000-0001-7935-9427 \\ Universidade Estadual do Sudoeste da Bahia, Brasil \\ E-mail: silviohgpv@gmail.com \\ Ninalva de Andrade Santos \\ ORCID: https://orcid.org/0000-0001-7051-7230 \\ Universidade Estadual do Sudoeste da Bahia, Brasil \\ E-mail: ninalvasantos@yahoo.com.br \\ Bárbara Santos Figueiredo Novato \\ ORCID: https://orcid.org/0000-0002-4653-840X \\ Universidad Central del Paraguay, Paraguai \\ E-mail:babynovato@yahoo.com \\ Raquel Soares Pedro \\ ORCID: https://orcid.org/0000-0001-6482-3557 \\ Universidade do Estado do Rio de Janeiro, Brasil \\ E-mail: soaresr395@gmail.com \\ Jane Marcia Progianti \\ ORCID: https://orcid.org/0000-0003-3843-5192 \\ Universidade do Estado do Rio de Janeiro, Brasil \\ E-mail: jmprogi@gmail.com \\ Eloá Carneiro Carvalho \\ ORCID: https://orcid.org/0000-0002-1099-370X \\ Universidade do Estado do Rio de Janeiro, Brasil \\ E-mail: eloagrossi@uol.com.br \\ Carolina Cabral Pereira da Costa \\ ORCID: https://orcid.org/0000-0002-0365-7580 \\ Universidade do Estado do Rio de Janeiro, Brasil \\ E-mail: carolcuerj@hotmail.com \\ Midian Dias Oliveira \\ ORCID: https://orcid.org/0000-0001-5378-736X \\ Universidade do Estado do Rio de Janeiro, Brasil \\ E-mail: dias.midian@gmail.com \\ Samira Silva Santos Soares \\ ORCID: https://orcid.org/0000-0001-9133-7044 \\ Universidade Federal do Rio de Janeiro, Brasil \\ E-mail: samira_opg@hotmail.com \\ Norma Valéria Dantas de Oliveira Souza \\ ORCID: https://orcid.org/0000-0002-2936-3468 \\ Universidade do Estado do Rio de Janeiro, Brasil \\ E-mail: norval_souza@yahoo.com.br
}

\begin{abstract}
Resumo
Objetivos: identificar as características da organização do trabalho hospitalar, na perspectiva dos trabalhadores de enfermagem, e analisar as repercussões da organização do trabalho hospitalar na subjetividade desses trabalhadores. Método: estudo qualitativo e descritivo cujos participantes foram 22 técnicos de enfermagem e 12 enfermeiros de uma unidade hospitalar de médio porte na região sudoeste da Bahia. Realizou-se a coleta por meio de entrevista semiestruturada e as informações foram tratadas à luz da técnica de análise temática de conteúdo. Resultado: verificou-se que a organização do trabalho torna o trabalhador polivalente e multifuncional; há significativo distanciamento entre o trabalho prescrito e o trabalho real, o que predispõe ao sofrimento do trabalhador. Constatou-se que existe precarização do trabalho e divisão técnica do trabalho que suscita conflitos de classe. Conclusão: a configuração da organização do trabalho predispõe mais ao sofrimento psicofísico do trabalhador do que contribui para proteger a subjetividade do coletivo profissional.
\end{abstract}

Palavras-chave: Saúde do trabalhador; Enfermagem; Condições de trabalho; Hospitais. 


\begin{abstract}
Objectives: to identify the characteristics of the organization of hospital work, from the perspective of nursing workers, and to analyze the repercussions of the organization of hospital work on the subjectivity of these workers. Method: qualitative, descriptive study whose participants were 22 nursing technicians and 12 nurses from a mediumsized hospital unit in the southwest region of Bahia. The collection was carried out through semi-structured interviews and the information was treated in the light of the thematic content analysis technique. Result: it was found that the organization of work makes the worker multipurpose and multifunctional. There is a significant gap between prescribed work and real work, which predisposes workers to suffering. It was found that there is precarious work and technical division of labor that causes class conflicts. Conclusion: The configuration of the work organization predisposes more to the psychophysical suffering of the worker than it contributes to protect the subjectivity of the professional group.
\end{abstract}

Keywords: Occupational health; Nursing; Work conditions; Hospitals.

\title{
Resumen
}

Objetivos: identificar las características de la organización del trabajo hospitalario, desde la perspectiva de los trabajadores de enfermería, y analizar las repercusiones de la organización del trabajo hospitalario en la subjetividad de estos trabajadores. Método: estudio cualitativo, descriptivo, cuyos participantes fueron 22 técnicos de enfermería y 12 enfermeras de una unidad hospitalaria de tamaño mediano en la región suroeste de Bahía. La recopilación se realizó mediante entrevistas semiestructuradas y la información se trató a la luz de la técnica de análisis de contenido temático. Resultado: se descubrió que la organización del trabajo hace al trabajador multipropósito y multifuncional. Existe una brecha significativa entre el trabajo prescrito y el trabajo real, lo que predispone a los trabajadores al sufrimiento. Se descubrió que existe un trabajo precario y una división técnica del trabajo que causa conflictos de clase. Conclusión: La configuración de la organización del trabajo predispone más al sufrimiento psicofísico del trabajador que contribuye a proteger la subjetividad del grupo profesional.

Palabras clave: Salud ocupacional; Enfermería; Condiciones de trabajo; Hospitales.

\section{Introdução}

A organização do trabalho hospitalar tem o potencial de gerar repercussões para a dimensão subjetiva dos trabalhadores de enfermagem. Compreende-se que o processo de reestruturação produtiva, sob a orientação do capital, produziu nas últimas décadas transformações na organização do trabalho que tornaram a realidade vivida pelo trabalhador cada vez mais complexa e hostil, impactando negativamente na subjetividade dos trabalhadores (Dejours, 2011).

A subjetividade refere-se aos sentimentos do ser humano em relação a alguma coisa ou a alguém. Ela é dinâmica, pois é construída e moldada ao longo da vida, a partir das vivências e experiências em vários contextos, isto é, na relação com a família, escola, igreja, trabalho, entre outros. Portanto, a subjetividade é construída e reconstruída a partir do convívio do indivíduo com o outro e com o coletivo. A subjetividade delineia a identidade de uma pessoa, seus gostos, anseios, idealizações, caracterizando o indivíduo em sua especificidade que, por sua vez, engendra sentimentos de prazer e sofrimento, satisfação e insatisfação, aderência ou repulsa, entre outras emoções e sentimentos que compõem a existência humana (Dejours, 2011).

Nessa perspectiva, o trabalho é um importante elemento na construção e reconstrução da subjetividade, visto que ele ocupa centralidade na vida das pessoas. Assim, por meio do trabalho, os seres humanos se relacionam, transformam a natureza e também se transformam. Nas sociedades, independentemente do local e da época, indivíduos desenvolvem atividades laborais, as quais denotam envolvimento dos seus corpos em atividades socialmente programadas, capazes de produzir os meios materiais para subsistência (Pereira \& Tolfo, 2016).

O modo de produção capitalista, iniciado no século XIX, vem passando por processo de reestruturação, modificando as condições de trabalho, especialmente as suas formas de organização e controle, produzindo intensos ritmos laborais, muitas vezes determinados pela demanda externa do consumo. Tal situação resulta, frequentemente, em elevadas exigências quanto à formação dos trabalhadores, por conseguinte também vem moldando comportamentos e disciplinas no local de trabalho, repercutindo em insólitas e complexas vivências laborais (Dejours, 2011). 
Corroborando, esse contexto fundamenta-se no princípio de que o livre mercado pode regular as esferas da vida cotidiana o qual, por sua vez, é norteado pelo ideário neoliberal de que o bem-estar tem como gênese a individualização do esforço, a competitividade entre os pares, a polivalência e multifuncionalidade do trabalhador. Nesse sentido, verificam-se impactos na dimensão subjetiva dos trabalhadores cujas evidências vêm mostrando trabalhadores com elevado sofrimento psíquico e potencial para o adoecimento mental, destacando-se a síndrome de burnout, a síndrome da servidão voluntária, depressão, ansiedade patológica, que vem conduzindo alguns trabalhadores ao suicídio (Campos, 2017; Silva, Bernardo, \& Souza, 2016).

Nessa perspectiva, o trabalho hospitalar também sofre influência do processo de reestruturação produtiva ao buscar novos padrões de produtividade para, sob a lógica do neoliberalismo, impor metas de produção, acirrar a competitividade entre os trabalhadores, intensificar os ritmos laborais e prolongar a jornada laboral com o objetivo de aumentar a produtividade. Com gestão verticalizada, no caso da enfermagem, enfatiza-se uma configuração laboral que se caracteriza pela remuneração inadequada, acumulação de escalas de serviço ou duplo vínculo, aumento da jornada de trabalho, desprestígio social da profissão, precariedade e insuficiência de recursos materiais, condição de trabalho insalubre, tensão e pressão psicológica (Padilha et al., 2017; Silva et al., 2020).

Mediante o exposto, emergiram as seguintes questões norteadoras: como se configura a organização do trabalho de um hospital público do sudoeste da Bahia sob a ótica dos trabalhadores de enfermagem? Quais são as situações de prazer e sofrimento que emergem dos trabalhadores de enfermagem quando discorrem sobre a organização do trabalho hospitalar?

Os objetivos do estudo foram identificar as características da organização do trabalho hospitalar, na perspectiva dos trabalhadores de enfermagem, e analisar as repercussões da organização do trabalho hospitalar na subjetividade desses trabalhadores.

\section{Metodologia}

Considerando a natureza do objeto de estudo, optou-se por uma pesquisa qualitativa e descritiva (Minayo, 2013).

O estudo foi desenvolvido no sudoeste do estado da Bahia. O campo foi um hospital geral de médio porte, que atende urgência/emergência, vinculado à gestão direta da Secretaria de Saúde do Estado da Bahia.

Os participantes foram enfermeiros, técnicos e auxiliares de enfermagem que possuíam vínculo empregatício efetivo, bem como contratados pela fundação estatal regidos pela Consolidação das Leis do Trabalho, e os de cargo comissionado. Constituíram critérios de exclusão: tempo de serviço na unidade inferior ou igual a um ano, pelo entendimento de que, em período inferior, o trabalhador ainda estaria aprendendo a dinâmica do campo de atuação profissional, podendo apresentar dificuldades para descrever sua configuração e a dinâmica de prazer e sofrimento oriunda da vivência laboral; afastamento do trabalhador devido à licença médica, licença-prêmio ou férias no momento da coleta de dados; trabalhadores terceirizados e recém-contratados pela empresa privada que assumiu a gestão da ala nova do hospital, inaugurada no início do ano de 2018.

A coleta de dados ocorreu entre maio e junho de 2018 com 34 participantes, dos quais 22 eram técnicos de enfermagem e 12, enfermeiros. Salienta-se também que se utilizou a técnica de snow ball ou de bola de neve para captação dos participantes. Sendo assim, o primeiro informante foi escolhido pela facilidade de acesso ao mesmo e, a partir dessa entrevista, captaram-se os demais participantes por indicação dos informantes anteriores (Patias \& Hohendorff, 2019). Os dados coletados ficarão armazenados em posse dos pesquisadores por um período de 5 anos, após este período serão incinerados.

Utilizando-se um roteiro de entrevista semiestruturada, as informações foram transcritas, analisadas e interpretadas à luz da técnica de análise temática de conteúdo (Bardin, 2010). Após a aplicação dessa técnica, emergiram duas categorias as quais foram denominadas da seguinte forma: Concepções sobre o trabalho; Sofrimento e prazer decorrentes da configuração 
organização do trabalho.

O estudo foi submetido e aprovado pelo Comitê de Ética da Universidade Estadual do Sudoeste da Bahia (parecer 2.414.553). Aos participantes do estudo foi entregue e solicitada a assinatura do Termo de Consentimento Livre e Esclarecido expondo o objetivo do estudo e, dentre outros aspectos, constava a garantia da confidencialidade dos dados, participação voluntária e o anonimato daqueles que participassem do estudo, conforme estabelece a Resolução 466/12.

Nessa perspectiva, a fim de garantir o anonimato dos participantes, utilizou-se uma codificação caracterizada pela letra $\mathrm{E}$ de entrevista, seguida de um número cardinal que evidenciava a sequência de realização das entrevistas. Dessa forma, o primeiro participante foi identificado como E1 e assim por diante.

\section{Resultados}

A apresentação dos resultados deu-se por meio das categorias anteriormente mencionadas, nas quais os aspectos relevantes para o alcance dos objetivos foram evidenciados mediante destaques dos recortes das falas dos participantes. Salienta-se que os 34 participantes tiveram representatividade nos pontos analisados nas duas categorias, no entanto selecionaram-se as falas mais significativas para exemplificar as análises efetuadas.

\subsection{Categoria 1: Concepções Sobre o Trabalho}

Os participantes do estudo citaram a divisão técnica do trabalho como influenciadora do fazer laboral, salientando que há uma demarcada divisão das atividades dos enfermeiros e dos técnicos e auxiliares de enfermagem.

"A gente chega e colhe os sinais vitais, a gente vai para o banho e curativos, nesses curativos a gente verifica quem é o enfermeiro que vai fazer este procedimento. Ou seja, os mais complexos o enfermeiro faz e os menos complicados o técnico executa." (E11).

Outro resultado que emergiu do conteúdo das entrevistas foi a concepção do significado do trabalho. O sentido do trabalho na modernidade vem permeado de subjetividade e influenciado pela sociedade de consumo, na qual se quer ter e conquistar bens materiais, buscando-se a aceitação e valorização social. Portanto, a materialidade e a subjetividade estão intrinsicamente ligadas e uma influência a outra.

“O trabalho para mim é onde eu tiro meu viver, a questão do dinheiro mesmo, da questão de verbas.” (E13).

"Hoje em dia, eu valorizo muito essa parte financeira, então se para eu me manter, para ter uma boa estabilidade, eu tenho que fazer um bom trabalho, então eu levo isso para os dois lados, porque um depende do outro." (E19).

Captou-se também a percepção de utilidade social e essencialidade que emerge do trabalho.

"O trabalho é fundamental para a realização pessoal como indivíduo, como pessoa, como cidadão porque ele é importante para a sociedade. Eu me realizo cuidando das pessoas, sem trabalhar ficaria uma lacuna em aberto na minha vida." (E15).

"Tem o significado de desempenho de atividades que é essencial para a sociedade, ou seja, o cuidado à pessoa doente. Assim, sinto que o trabalho é como uma meta de atingir uma satisfação tanto pessoal como do outro." (E33). 


\subsection{Categoria 2: Sofrimento e Prazer Decorrentes da Configuração da Organização do Trabalho}

Os participantes atribuíram concepções negativas relativas à organização do trabalho que resultavam em desconforto e sofrimento aos trabalhadores de enfermagem. Assim, destacam-se a sobrecarga de trabalho física e mental, pressão por maior produtividade, atuação com chefias autoritárias e punitivas. A fala descrita caracteriza tal resultado:

"Eu acho que é o dimensionamento de pessoal que é muito errado, que por sinal gera sobrecarga de trabalho e conflitos com a gerência. É muito para uma pessoa só, que leva a uma pressão no nosso lado físico, psicológico e mental. Literalmente está longe de ser o ideal." (E11).

Ressalta-se, também, que o modo de produção capitalista tem sido reproduzido na divisão do trabalho hospitalar com tarefas isoladas, fragmentadas, com hierarquia profissional rígida e separação de trabalho intelectual e manual, desencadeando maior exigência mental do trabalhador, como observado nas falas a seguir:

"Sobrecarga de trabalho e pressão psicológica. Hoje em dia, principalmente, com essa pressão por produzir e produzir, surge o adoecimento." (E13).

"Aqui a gente não tem válvula de escape, aqui a gente tem pressão. Eu acho que o hospital perdeu muito a questão do diálogo, infelizmente. Realmente a gente já vive em um ambiente estressante por termos muito trabalho, pouco profissional e cobrança da chefia o tempo todo." (E23).

Verificou-se também o distanciamento entre o trabalho prescrito e o trabalho efetivo como fonte de sofrimento para o trabalhador. A situação resulta de ocorrências como falha de equipamentos, disfunção, incidentes e sobrecarga de trabalho. Exemplifica-se a seguir:

"O trabalhador vem para a instituição achando que está tudo dentro dos padrões, ai a realidade é outra, então ele tem uma pressão psicológica emocional, dentro do contexto do trabalho. Ele se nega ou se esquiva de fazer o procedimento porque literalmente faltam condições materiais e de pessoal. De uns tempos para cá, percebe-se que não estão contentes, estão ali para fazer só o necessário, não vai além. " (E33).

Salientou-se a sobrecarga de trabalho em razão da deficiência de mão de obra e grande demanda de atendimento.

"Na clínica médica a gente trabalha muito, o trabalho físico, forçado, aquele trabalho mais forte, mais pesado, com ritmo de trabalho muito grande." (E19).

"Ficavam dois técnicos para 14, 16 pacientes, logo, o atendimento era precário. Daí, temos a sobrecarga profissional, que até acaba gerando descaso para o paciente, pois a gente não conseguia dar uma assistência digna para eles." (E21).

Outro aspecto ressaltado no conteúdo das entrevistas foi o assédio moral vivenciado por trabalhadores de 
enfermagem. Abordou-se o fato de os trabalhadores estarem entristecidos e com risco ao isolamento e adoecimento.

"Ultimamente há uma liderança que se o funcionário estiver sentado olhando o celular, é motivo de advertência, como se você não estivesse fazendo nada. Isso adoece. Vem trabalhar contente, mas com essa situação de repressão constante, adoece. Quem não tem poder de se expressar, enfrentar, fica acuado, isolado e adoece." (E33).

Outra situação negativa referente à organização do trabalho foi a comunicação ineficaz, geradora de incertezas para os trabalhadores.

"Porque essa questão do disse me disse no corredor, isso acaba com a gente, é chamar e te explicar o que está acontecendo, sentar com a equipe e explicar, olha vai acontecer isso, você vai para tal setor, para você não ficar nessa agonia, na incerteza." (E6).

"Acho que o problema maior nosso é a comunicação. As pessoas não se comunicam, não se posicionam e vai acumulando as questões emocionais.” (E9)

Repercussões positivas foram evidenciadas a partir da configuração da organização do trabalho. Emergiram nas falas bom relacionamento interpessoal entre membros da equipe, mudança de ambiente devido à reestruturação física do hospital e pelo respeito à hierarquia.

"O relacionamento com a equipe em si é a melhor parte do trabalho, estou numa equipe que eu não tenho o que reclamar, todo mundo se dá muito bem, todo mundo confia na tarefa do outro." (E15).

"A Clínica Médica é diferente da que eu encontrei, o ambiente físico mudou, a equipe mudou, a coordenação influenciou muito nisso, eu acho que até o conceito das outras unidades em relação à clínica médica mudou. A gente pode não ter o perfeito, mas hoje tem mais recursos do que a gente tinha." (E12).

Outro ponto positivo relacionado à organização do trabalho e que predispõe à sensação de prazer foi a importância de se ter um ambiente organizado para melhor fluidez do trabalho e a priorização do cuidado ao paciente. Essa análise foi caracterizada com a fala explicitada a seguir:

"Eu chego às 7 h no meu plantão e tem toda uma arrumação do setor em que estou. Coloco todos os materiais do jeito que vou utilizar, me dirijo à sala da emergência pediátrica para dar bom dia aos meus colegas. Ou seja, a organização do ambiente é fundamental e vejo que outros profissionais seguem esta rotina." (E31).

\section{Discussão}

Como herança do taylorismo, tem-se a organização do trabalho, com divisão entre trabalho manual, de incumbência dos operários, e o trabalho intelectual, de incumbência da gerência (Morais \& Moura, 2017).

$\mathrm{Na}$ enfermagem, a divisão técnica do trabalho entre trabalho manual e intelectual evoca ao enfermeiro as atividades gerenciais, de supervisão e de execução de procedimentos mais complexas; e aos auxiliares e técnicos, atividades manuais e de caráter mais simples. Essa concepção contribui para a perpetuação das relações de dominação de enfermeiros para com 
técnicos e auxiliares usando, muitas vezes, dessa concepção para a cobrança por cumprimento de metas e acirrando as relações de poder e lutas de classes. Além disso, tem-se que o trabalho manual é mais penoso, tornando a atividade dispendiosa e, frequentemente, adoecedora (Dutra, 2016).

Portanto, a organização laboral que se vale da divisão de tarefas, fragmentando o trabalho, enfraquece a coesão do coletivo profissional, captura a subjetividade do trabalhador em favor da produtividade e ainda embota a capacidade reflexiva e crítica da força de trabalho (Dejours, 2011).

Pondera-se que o labor, embora tenha passado por diversas mudanças, prossegue mantendo elevada importância, sendo fonte de provisão de renda, produtividade, significação do ser humano, forma de ascensão e obtenção de respeito social, o que faz emergir sentimento de prazer (Schmidt, Barbosa, Pinceli, \& Lucca, 2017). Porém, há de se ter cuidado com tal concepção, pois quando a atividade produtiva representa somente o "ganha pão", sem relevar o valor subjetivo do trabalho, pode ocorrer um sentimento de sofrimento com potencial para o adoecimento do trabalhador (Rodrigues, Barrichelo, \& Morin, 2016).

De outro modo, captou-se que o trabalho não é apenas fonte de subsistência material. É também um meio que torna o ser humano útil para a sociedade, possibilitando a inserção em um grupo, fortalecendo o sentimento de pertencimento social, considerando a relevância da atividade executada. Tal concepção é um forte protetor da subjetividade do trabalhador, uma vez que faz emergir sentimento de prazer (Dejours, 2011).

O sofrimento psíquico decorrente da organização laboral vem se relacionando às concepções neoliberais no trabalho hospitalar, destacando-se o enxugamento da máquina pública que reduz o quantitativo de pessoal e de material. Além disso, verifica-se o achatamento da remuneração dos trabalhadores e a imposição de metas elevadas para a produtividade em saúde. Tal situação aumenta a demanda laboral e intensifica os ritmos de trabalho. Ademais, constatam-se chefias que, na busca por atingir metas, pressionam o trabalhador elevando as cobranças, sem levar em consideração as especificidades psicofísicas do trabalhador (Rossi \& Akimoto, 2018).

O modo de produção capitalista tem adentrado nas organizações hospitalares com características de aumento da produtividade, configurando-se em individualização do sujeito com aprisionamento da subjetividade do trabalhador e exploração do trabalho humano, acompanhado pela precarização. Coloca-se também em voga a questão econômica que se estabelece para alcance de metas e produtividade, em que quanto mais se executa determinada tarefa, maior lucro é atribuído a determinado serviço (Campos, 2017; Teston, Mendes, Carnut, \& Junqueira, 2018).

Evidencia-se também que o distanciamento entre a organização prescrita do trabalho e a real é fonte de sofrimento. Assim, os trabalhadores se deparam com normas que na configuração real do trabalho fica difícil de alcançar ou cumprir. Dessa forma, tem-se uma organização do trabalho que por falta de condições laborais e por distanciamento sobre o que efetivamente acontece na dinâmica do trabalho imputa no trabalhador um sofrimento decorrente de frustação pela não realização do trabalho idealizado como correto (Lima et al., 2017).

A organização do trabalho contemporâneo fundamenta-se predominantemente no modelo neoliberal, que preconiza uma estrutura produtiva flexível, de trabalhadores polivalentes e multifuncionais, prontos para responder às diversas demandas de trabalho, com elevada intensificação do ritmo laboral devido ao aumento da necessidade de produção (Jesus et al., 2016). Logo, a sobrecarga de trabalho faz com que trabalhadores desenvolvam ritmo de trabalho intenso, gerando riscos à saúde.

O ideário neoliberal frequentemente tem seu sustento na gestão pelo medo, abuso de poder, por meio do assédio moral e da discriminação criada pela terceirização (Antunes \& Druck, 2015). A enfermagem vivencia muitas situações de assédio moral, individualmente ou em grupo, decorrente da atitude de chefias autoritárias, inflexíveis e irracionais, sendo que o assédio moral propicia ao trabalhador desinteresse pelo trabalho, surgimento de estado patológico ou agravamento se este já for existente (Jesus et al., 2016). 
O assédio moral é uma situação de violência psicológica que ocorre no ambiente laboral, podendo acontecer de forma silenciosa e perversa, sendo episódios repetitivos que ferem a integridade psíquica e física do indivíduo. Estudos apontam que episódios de assédio são maléficos para a vítima e para quem assiste, gerando sentimentos como revolta, estresse, tristeza, sentimento de perseguição, perda de apetite e alteração em padrão do sono, além do fato de malefícios para a organização do trabalho à medida que expõe profissionais ao desânimo e ao medo (Lucena et al., 2019).

$\mathrm{Na}$ organização hospitalar, constatou-se a importância da comunicação. Esta tem papel fundamental fazendo parte das organizações laborais para que processos sejam continuados, sendo também importante na interação entre as pessoas e, sobretudo, na área de saúde onde a falha na comunicação pode comprometer a vida dos indivíduos. Assevera-se a importância da comunicação eficaz e eficiente, visto que gera menos tensão e conflito nas organizações laborais, contribuindo como facilitadora para qualidade da assistência e para a saúde dos trabalhadores (Silva, Anders, Rocha, Souza, \& Burciaga, 2016).

Faz-se salutar evocar a manutenção do bom relacionamento interpessoal entre pares como fator protetivo em situações possivelmente danosas aos trabalhadores decorrentes do processo produtivo. Em ambientes de trabalho competitivos e hierarquizados, é fundamental que boas relações sejam construídas a fim de que se aumente a qualidade de vida no trabalho e haja proteção da saúde mental dos trabalhadores, sendo evidenciado que, em situações com falhas no relacionamento, os profissionais são passíveis de desânimo, estresse e síndrome de burnout e desgaste nas relações no ambiente laboral (Dias et al., 2019; Conz et al., 2019).

Também é considerado fator protetivo para o trabalhador a disposição arquitetônica do ambiente de trabalho. Há necessidade de ambientes de trabalho facilitadores do processo de trabalho, onde os riscos ergonômicos sejam cessados e o trabalhador encontre segurança (Gouveia, Oliveira, \& Lira, 2019). Dessa forma, tem-se a ambiência assumindo papel primordial nos espaços de cuidado, com confortabilidade no local onde relações são estabelecidas, com valor a fatores como cheiro, iluminação, som e provisão de materiais de trabalho bem dispostos, além de ser constitutivo da produção de subjetividade dos indivíduos (Glanzner \& Olschowsky, 2017).

\section{Considerações Finais}

A organização do trabalho investigada fundamenta-se predominantemente em uma lógica neoliberal, que intensifica os ritmos de trabalho, que torna o trabalhador polivalente e multifuncional, que pressiona fortemente o trabalhador para produzir mais e melhor e, portanto, torna as relações interpessoais tensas por conta das cobranças da gerência. Ademais, verificam-se relações hierárquicas intensamente demarcadas abrindo precedentes para o assédio moral e para a violência no trabalho. Outrossim, constatou-se o distanciamento entre o trabalho prescrito e o real, que se caracteriza como fator de sofrimento psicofísico.

Assim sendo, salienta-se que a configuração dessa organização laboral predispõe mais ao sofrimento do que ao prazer, visto que se elencaram inúmeras situações que se chocam com a subjetividade dos trabalhadores, ou seja, com suas concepções e idealizações de como se deve executar a tarefa laboral.

As percepções positivas da organização do trabalho vinculam-se ao bom relacionamento interpessoal entre membros da equipe, mudança de ambiente por conta da reestruturação e revitalização da planta física, atenção a aspectos ergonômicos no ambiente laboral, proporcionando prazer no trabalho.

Evidenciou-se também que outra situação que remonta ao prazer está relacionada ao objeto de trabalho da enfermagem, o cuidado ao ser humano, cuja atividade faz o trabalhador sentir-se útil para sociedade. Porém, este é um elemento mais vinculado ao processo laboral da profissão e pouco relacionado com a configuração da organização do trabalho.

Recomenda-se que as organizações do trabalho hospitalar adotem medidas preventivas para proteger a subjetividade 
dos profissionais, oferecendo-lhes adequadas condições de trabalho no tocante a materiais, equipamentos e dimensionamento de pessoal. Ressalta-se a importância de que gestores repensem as relações de trabalho quanto ao exercício do poder e, principalmente, a forma de lidar com o sofrimento do trabalhador e as suas consequências para o sujeito e a coletividade.

Considerou-se como limitação desta pesquisa o fato de ter sido realizada no contexto de uma única instituição pública de saúde, carecendo de um maior aprofundamento dessa problemática em outras realidades do país e do próprio estado da Bahia, podendo, assim, obter resultados mais generalizáveis.

Espera-se que o estudo contribua para compreensão, em maior profundidade, da complexidade que envolve o mundo do trabalho atual, fortemente embasado no ideário neoliberal, e seus impactos na subjetividade dos trabalhadores. Ademais, acredita-se que os resultados apreendidos sirvam de subsídio para elaboração e implementação de ações de caráter preventivo, reduzindo, dessa forma, agravos à saúde de trabalhadores de enfermagem, bem como melhorias nas condições laborais e no avanço da qualidade da assistência de saúde.

\section{Referências}

Antunes, R., \& Druck, G. (2015). A terceirização sem limites: a precarização do trabalho como regra. O Social em Questão, 34, 19-40. http://www.cressrn.org.br/files/arquivos/Sm4618UP754c17102374.pdf

Bardin, L. (2010). Análise de conteúdo. Edições 70.

Campos, M. R. (2017). Trabalho, alienação e adoecimento mental: as metamorfoses no mundo do trabalho e seus reflexos na saúde mental dos trabalhadores. Revista de Políticas Públicas, 21(2), 797-812. http://dx.doi.org/10.18764/2178-2865.v21n2p797-812

Conz, C. A., Aguiar, R. S., Reis. H. H., Pinto. M. C. J., Mira, V. L., \& Merighi, M. A. B. (2019). Atuação de enfermeiros líderes de unidade de terapia intensiva: abordagem compreensiva. Enfermagem em Foco, 10(4), 41-46. http://biblioteca.cofen.gov.br/wp-content/uploads/2020/03/2196-15368-1-PB.pdf

Dias, J. S., Rocha, L. P., Carvalho, D. P., Tomaschewski-Barlem, J. G., Barlem, E. L. D., \& Dalmolin, G. L. (2019). Construction and validation of a tool to assess nursing interpesonal relations. Revista Brasileira de Enfermagem, 72(2), 408-413. https://doi.org/10.1590/0034-7167-2018-0229

Dejours, C. (2011). Da psicopatologia à psicodinâmica do trabalho. Fiocruz.

Dutra, H. S. (2016). Social division of work and nursing. Revista de Enfermagem UFPE on line, 10(11), 4161-4163. https://doi.org/10.5205/1981-8963v10i11a11503p4161-4163-2016

Glanzner, C. H., \& Olschowsky, A. (2017). A ambiência e sua influência no trabalho de equipes de saúde da família. Saúde e Desenvolvimento Humano, 5(1), 7-14. http://dx.doi.org/10.18316/sdh.v5i1.2880

Gouveia, M. T. O., Oliveira, V. C., \& Lira, M. S. (2016). Riscos ergonômicos em um centro de material e esterilização. Revista de Enfermagem UFPI, 5(3), 42-47. https://doi.org/10.26694/reufpi.v5i3.5427

Jesus, M. A. C., Souza, N. V. D. O., Costa, C. C. P., Carvalho, E. C., Gallasch, C. H., \& Souza, P. H. D. O. (2016). Psychological harassment in the hospital nursing workplace: na integrative literature review. Revista de Enfermagem UERJ, 24(4), 1-6. http://dx.doi.org/10.12957/reuerj.2016.26437

Lima, A. M., Inneco, C. S., Moreno, D. C., Itami, J. K., Giovanni, J. C. F., \& Souza, P. H. D. O. (2017). Diagnóstico organizacional e as contribuições da psicologia do trabalho. Revista de Ciências Gerenciais, 21(33), 23-30. https://doi.org/10.17921/1415-6571.2017v21n33p23-30

Lucena, P. L. C., Costa, S. F. G., Batista, J. B. V., Araújo, E. L. M., Soares, C. C. D., \& Rolim, R. M. G. C. (2019). Testemunhas de assédio moral, na enfermagem: identificando características desse fenômeno, sentimentos e estratégias de enfrentamento. Revista Mineira de Enfermagem, 23 , e-1164. http://www.dx.doi.org/10.5935/1415-2762.20190012

Minayo, M. C. S. (Org.). (2013). Pesquisa social: teoria, método e criatividade. Vozes.

Morais, J. K. C., \& Moura, D. H. (2017) Do taylorismo/fordismo à acumulação flexível: implicações dos regimes de acumulação para o mundo do trabalho. Revista Labor, 1(17), 62-72. http://www.repositorio.ufc.br/bitstream/riufc/28583/1/2017_art_jkcmoraisdhmoura.pdf

Padilha, K. G., Barbosa, R. L., Andolhe, R., Oliveira, E. M., Ducci, A. J., Bregalda, R. S., \& Secco, L. M. D. (2017). Carga de trabalho de enfermagem, estresse/burnout, satisfação e incidentes em unidade de terapia intensiva de trauma. Texto Contexto - Enfermagem, 26(3), e1720016. http://dx.doi.org/10.1590/0104-07072017001720016

Patias, N. D., \& Hohendorff, J. V. (2019). Critérios de qualidade para artigos de pesquisa qualitativa. Psicologia em Estudo, 24 , e43536. https://dx.doi.org/10.4025/psicolestud.v24i0.43536

Pereira, E. F., \& Tolfo, S. R. (2016). Estudos sobre sentidos e significados do trabalho na psicologia: uma revisão das suas bases teórico-epistemológicas. Psicologia Argumento, 34(87), 302-317. http://dx.doi.org/10.7213/psicol.argum.34.087.AO02 
Research, Society and Development, v. 10, n. 2, e50910212746, 2021

(CC BY 4.0) | ISSN 2525-3409 | DOI: http://dx.doi.org/10.33448/rsd-v10i2.12746

Rodrigues, A. L., Barrichelo, A., \& Morin, E. M. (2016). Os sentidos do trabalho para profissionais de enfermagem: um estudo multimétodos. Revista de Administração de Empresas, 56(2), 192-208. https://doi.org/10.1590/S0034-759020160206

Rossi, H. C., \& Akimoto, C. K., Jr. (2018). Neoliberalismo e sujeito: construção da identidade, ressignificação do sofrimento e exclusão da diferença. Revista da Faculdade de Direito, Universidade de São Paulo, 113, 761-774. https://doi.org/10.11606/issn.2318-8235.v113i0p761-774

Schmidt, M. L. G., Barbosa, W. F., Pinceli, S. C. C., \& Lucca, S. R. (2017). Meanings and senses of work: reflections for the role of the occupational physicians in contemporaneity. Revista Psicologia, Diversidade e Saúde, 6(2), 138-142. doi http://dx.doi.org/10.17267/2317-3394rpds.v6i2.1284

Silva, M. F., Anders, J. C., Rocha, P. K., Souza, A. I. J., \& Burciaga, V. B. (2016). Comunicação na passagem de plantão de enfermagem: segurança do paciente pediátrico. Texto \& Contexto - Enfermagem, 25(3), e3600015. https://doi.org/10.1590/0104-07072016003600015

Silva, M. P., Bernardo M. H., \& Souza, H. A. (2016). Relações entre saúde mental e trabalho: a concepção de sindicalistas e possíveis formas de enfrentamento. Revista Brasileira de Saúde Ocupacional, 41, 1-12. https://doi.org/10.1590/2317-6369000003416

Silva, R. M., Vieira, L. J. E. S., Garcia Filho, C., Bezerra, I. C., Cavalcante, A. N., Borba Netto, F. C., \& Aguiar, F. A. R. (2020). Precarização do mercado de trabalho de auxiliares e técnicos de enfermagem no Ceará, Brasil. Ciência \& Saúde Coletiva, 25(1), 134-145. http://dx.doi.org/10.1590/141381232020251.28902019

Teston, L. M., Mendes, A., Carnut, L., \& Junqueira, V. (2018). Avaliação no SUS: uma crítica à ideologia do produtivismo no capitalismo contemporâneo. Saúde Debate, 42 (spe3), 226-239. https://doi.org/10.1590/0103-11042018s317 